sanitation facilities. The paper explores the pre-existing indirect factors responsible for the spread of outbreak in the provinces. These range from geography, socio-economic conditions, demographic features, topography, and community infrastructure. These factors play an extremely pivotal role in determining the nature of response required to control the diarrheal outbreak.

Prehosp Disaster Med 2011;26(Suppl. 1):s73-s74

doi:10.1017/S1049023X11002512

(A268) Lessons Learned: Western Australia's Health Sector Resilience during a Severe Storm M.G. Leclercq, ${ }^{1}$ A.G. Robertson ${ }^{2}$

1. Disaster Preparedness and Management Unit, East Perth, Australia

2. Disaster Management, Regulation and Planning, East Perth, Australia

The impacts of disasters on the community are not necessarily determined by the scale of a disaster, but are influenced significantly by the preparedness of the community, including the health community. Resilience is a dynamic quality within a community that is developed and strengthened over time. Evidence of the Western Australian (WA) health system resilience was demonstrated on 22 March 2010 when two severe weather fronts crossed the Perth metropolitan area and severely impacted a significant number of hospitals, the State pathology service, radiological services in tertiary and secondary hospitals, as well as aged care, mental health and other key health facilities. This storm has resulted in more than 120,000 claims and the total estimated cost is expected to exceed 1 billion Australian dollars, making it the most costly disaster due to natural hazards in WA history. Damage to these facilities included: (1) flooding, ceiling collapse, and broken windows in intensive care units, emergency departments, and operating theatres; (2) loss of radiological services; (3) sewerage inflow into wards, resulting in evacuation of mental health inpatients; (4) infrastructure damage to aged care facilities requiring relocation of residents; and (5) extensive loss of electricity and communications throughout Perth, which impacted on home oxygen therapy clients. A public health response also was required due to sewerage overflow into Perth's main river systems. This presentation will provide an overview of the event, lessons learned and how these lessons learned will be used to further enhance the health community's resilience.

Prehosp Disaster Med 2011;26(Suppl. 1):s74

doi:10.1017/S1049023X11002524

\section{(A269) Lightning Injuries: A Case Series} C. Yih Chong Michael, B. Russelle, G. Hsin Kai

Emergency Department, Singapore, Singapore

Background: Singapore, albeit a small country, has one of the highest lightning activities in the world. However, injuries related to this spectacular weather phenomenon are underreported and rarely a subject of study. Most reported cases dealt with lightning-caused fatalities but lightning-caused accidents are not always fatal. Actual reported international data showed that about $80 \%$ of lightning victims survived, with or without after effects. This study reviewed the cases of lightning-related injuries who presented to Tan Tock Seng Hospital, Emergency department.
Methods: This is a case series of 5 patients. All 5 patients presented to Tan Tock Seng Hospital, Emergency Department after a thunderstorm. All were undergoing military training when the incident happened. The circumstances surrounding their injury and their presentation and symptomatology were reviewed.

Results: In our study, three possible mechanisms of injury were identified through a side flash which occurred when the lightning hit the tree and traveled partly down that tree before a portion jumped to the nearby victims; through the concussive effect of the shock waves produced by the lightning; and through step voltage mechanism wherein the lightning after hitting the tree traveled into the ground where victims were standing. Two patients were diagnosed with rhabdomyolysis, one suffered from sensory-neural hearing loss, and one patient had a mild conjunctivitis as a result of tissue inflammation. Other symptoms included retrograde amnesia, parasthesia, tinnitus, and a single episode of seizure which resolved spontaneously. All our patients survived the ordeal and were discharged well back to their premorbid states.

Conclusion: This paper supports existing evidence that lightningcaused accidents are not always fatal and that victims may survive with no or little side effects given proper medical treatment.

Prehosp Disaster Med 2011;26(Suppl. 1):s74

doi:10.1017/S1049023X11002536

(A270) Medical Reserve Corps, American Red Cross, and a University: Lessons Learned from their Partnership during the Ice Storm

D.J. Persell

School of Nursing, State University, United States of America

The winter of 2009 brought the worst disaster caused by a natural hazard in the history of the state of Arkansas. An ice storm spanned the entire northern half of the state, leaving thousands without electricity, heat, transportation, health care, and in some cases, shelter, food, and water. In one county alone, $>13,000$ power poles were destroyed. The infrastructure was severely damaged. In the University's arena, a shelter was opened by the Red Cross in partnership with the Medical Reserve Corps (MRC) to accept special needs victims and provide urgent primary care for shelter residents. The majority of patients presenting to the MRC had more than two illnesses. Examples included diabetes, renal disease requiring dialysis, hypertensive crisis, injuries from the storm, MRSA, respiratory syncytial virus, and mental illness ranging from depression to schizophrenia. Because the Red Cross did not consider ice storms as a reasonable cause for medication $/ \mathrm{medi}$ cation supplies, these items were not replaced; this had health consequences of under-managed illness. Oxygen converters were preferred over oxygen tanks; however, the arena was on a generator and not all plug-ins had electricity. An ambulance company loaned the MRC a glucometer so blood glucose levels could be monitored. Those with mental illness required significant time from MRC providers. Largely, the MRC was nurse-managed with physicians or nurse practitioners available for sick call twice a day. Relationships became strained when the state placed a hold on the arena to secure it for a regional shelter. This put the university's financial stability in peril due to breech of contract with vendors scheduled to use the 
arena. The partnership between these three organizations does remain intact with formal memorandums of agreement now existing. They continue to work together in the community and jointly respond to regional disasters.

Prehosp Disaster Med 2011;26(Suppl. 1):s74-s75

doi:10.1017/S1049023X11002548

(A271) Building Resilient Healthcare Systems during Natural Disasters - Impacts of the 2007 Tulsa, Oklahoma Ice Storm

J. Gulden, ${ }^{1}$ B. Pond, ${ }^{2}$ M.K. Stewart, ${ }^{2}$ C.E. Stewart ${ }^{2}$

1. Emergency Management Support, M5G2V1, Canada

2. Department of Emergency Medicine, 74137, United States of America

On the evening of 07 December 2007, an ice storm occurred in the south central United States, causing severe power outages in Tulsa, Oklahoma, and leaving $>900,000$ people without power for up to three weeks. Eighteen states contributed power workers to restore functioning power over a three-week period. Cleanup of debris from fallen trees took an additional five months. Hospitals and other healthcare facilities are considered to be critical infrastructure facilities in the community. During this storm, five of the six tertiary care hospitals lost power. In these hospitals, the internal telephone systems failed, internal suctioning systems failed, and the internal oxygen system failed. Water treatment plants were without power for 48 hours. Nursing home patients were discharged to homes or transferred to hospitals, as nursing homes tried to function without power for heating, patient monitoring devices, or cooking. Communication for these outlying care facilities was disrupted by the storm damage. Hospital emergency departments that had power became havens as they had heat, communication, water, and even warm food. Multiple patients with injuries due to cleaning up tree debris, falls, and carbon monoxide poisoning from ill-advised efforts to heat dwellings were seen in these emergency departments. Ambulance services had fuel shortages early in the course of the ice storm due to the inability to pump fuel (electrically operated pumps initially were non-functional). Three standards of care were altered for prehospital responders. This paper explains the efforts taken to mitigate future calamities, based on the lessons learned from this event.

Prehosp Disaster Med 2011;26(Suppl. 1):s75 doi:10.1017/S1049023X1100255X

(A272) Socioeconomic Impact of "Hurricane Karl" on Health Facilities in Veracruz, Mexico with a Population of 7 Million 600 Thousand in September 2010

\section{P. Cruz Flores}

Escuela De Medicina, Sta. Catarina Mártir. Cholula, Puebla., Mexico

Socioeconomic impact of "Hurricane Karl" on health facilities in Veracruz, Mexico with a population of 7 million 600 thousand in September 2010 Summary Hurricane Karl, thirteenth tropical cyclone of the season in the Atlantic hurricane of 2010, originated in the Caribbean Sea and slammed into the Yucatan Peninsula as a strong tropical storm, to emerge into the Gulf of Mexico where it gradually reorganized to achieve Category 3 (major hurricane) on the Saffir-Simpson scale and hit the east coast of Mexico on September 17th of 2010. Preparations On September 16th, the Federal Government, Federal Electricity Commission, Laguna Verde Nuclear Power Plants, The Ministry of National Defense, The Ministry of Marine Affairs and human elements and materials deployed for relief to the population. The health sector also was prepared to take appropriate measures under the concept of Safe Hospital PAHO / WHO. Impact In the state of Veracruz (more than 7 million 600 thousand habitants), Hurricane Karl arrived around 11:30 am on September 17th to $15 \mathrm{~km}$ north of the port of Veracruz reaching a capacity of $195 \mathrm{~km}$ per hour. Torrential rains flooded the streets of the phenomenon and avenues of the historic center of the port, the water reached 40 centimeters to 1 meter in height, to the south of the state and surrounding areas reached 2 meters in height. Caused serious damage since its inception in health infrastructure, such as suspension of public services, damage to the distribution system of drinking water, broken windows and flooding of a hospital as well as several units of Family Medicine.

Prehosp Disaster Med 2011;26(Suppl. 1):s75

doi:10.1017/S1049023X11002561

(A273) Mass Gatherings and the Application of the New International Risk Management Standard ISO3100 M.W. Hills

Specialist Medical Manager, Redfern, Australia

Background: Early involvement by health services in the planning, preparation, operations and post-event analysis of mass gatherings provides one of the best opportunities to engage with other agencies and to develop a real sense of your agency's capabilities. The establishment of the new ISO Standards on Risk Management provide the best opportunity in a decade to structure this work in a manner that will develop true capacity to manage the multitude of risks health services face this century.

Discussion: Rather than ad hoc and sometimes conflicting approaches we now have the "lingua franca" on which to build our policy, capacity development, budgets and response. The evolution of risk management standards has seen the release of ISO 31000: 2009, Risk management - Principles and guidelines and ISO 31010: 2009, Risk management - Risk assessment techniques. Largely based on the earlier Australian Standard 4360 and work of the IEC these standards have the potential to embed critical aspects of the responsibilities of health agencies worldwide into a universal singular policy framework. Translating this into other areas of health agencies work includes communicable disease management and emergency management, in general, which will allow other agencies to understand the "health" perspective and vice versa.

Conclusions: Drawing on personal experiences from mass gatherings since 1997, the author will demonstrate the utility of the ISO Standards as the framework for health emergency management including mass gatherings. Examples will include mass gatherings at the international level within the Asia- Pacific Region to the local level within Sydney, Australia from 1997 to 2010 .

Prehosp Disaster Med 2011;26(Suppl. 1):s75 doi:10.1017/S1049023X11002573 